\title{
Cellular Physiology

\section{The Cardioprotective Effect of Brief Acidic Reperfusion after Ischemia in Perfused Rat Hearts is not Mimicked by Inhibition of the $\mathrm{Na}^{+} / \mathrm{H}^{+}$ Exchanger NHE1}

\author{
Ann-Dorit Andersen ${ }^{1, *}$, Bo Hjorth Bentzen ${ }^{2, *}$, Henrik Salling ${ }^{1}$, Henrik \\ Klingberg ${ }^{1}$, Morten Kanneworff ${ }^{3}$, Morten Grunnet ${ }^{2,4}$ and Stine F. \\ Pedersen $^{1}$

\begin{abstract}
${ }^{1}$ Section for Cell and Developmental Biology, Department of Biology, University of Copenhagen, Copenhagen, ${ }^{2}$ Danish National Research Foundation Centre for Cardiac Arrhythmia, University of Copenhagen, Copenhagen, ${ }^{3}$ Novo Nordisk A/S, Søborg, ${ }^{4}$ NeuroSearch A/S, Ballerup, *Contributed equally to this work
\end{abstract}

\section{Key Words}

JNK • p38 MAPK • Akt/protein kinase B • Ischemia/ reperfusion $\cdot \mathrm{HL}-1$ cells $\cdot$ Postconditioning

\begin{abstract}
Background: Ischemic postconditioning (PostC), i.e. brief ischemia-reperfusion cycles before full reperfusion, is protective against cardiac ischemia/ reperfusion (I/R) injury. Inhibition of the $\mathrm{Na}^{+} / \mathrm{H}^{+}$ exchanger NHE1 and delayed intracellular $\mathrm{pH}$ normalization have been proposed to underlie protection by PostC. Methods and Results: We used Langendorff perfused rat hearts exposed to $35 \mathrm{~min}$ global ischemia to show that 15 min acidic ( $\mathrm{pH} \mathrm{6.5)}$ treatment at onset of reperfusion decreased infarct size and functional deterioration at least to the same extent as PostC. In contrast, NHE1 inhibition by EIPA was detrimental. To evaluate $\mathrm{HL}-1$ atrial cardiomyocytes as a cellular model for PostC, we exposed the cells to simulated ischemia/reperfusion (I/R) mimicking that in perfused hearts. Necrosis and apoptosis induced by $\mathrm{I} / \mathrm{R}$ were unaffected by $15 \mathrm{~min}$ of $\mathrm{pH} 6.0$ at onset of reperfusion. I/R increased the activity of c-Jun N-terminal Kinase 1/2 (JNK1/2) and Akt, but not
\end{abstract}

\section{KARGER}

Fax +4161306 1234

E-Mail karger@karger.ch

www.karger.com
(C) 2011 S. Karger AG, Basel

1015-8987/11/0281-0013\$38.00/0

Accessible online at:

www.karger.com/cpb of p38 MAPK, with no further effect of acidic reperfusion or EIPA. Conclusion: In rat hearts, $15 \mathrm{~min}$ acidic reperfusion improves myocardial performance at least as much as does PostC, whereas NHE1 inhibition is detrimental. In contrast, in $\mathrm{HL}-1$ cardiomyocytes, acidic reperfusion or NHE1 inhibition affect neither survival nor JNK1/2-, Akt-, and p38 MAPK activity after $\mathrm{I} / \mathrm{R}$, pointing to different mechanisms of damage and protection in these systems.

Copyright (c) 2011 S. Karger AG, Basel

\section{Introduction}

Acute coronary artery occlusion resulting in myocardial ischemia and infarction is a major cause of death world-wide. Reperfusion is a prerequisite for recovery, yet injury initiated during the reperfusion phase accounts for a large fraction of the cardiomyocyte damage and death following myocardial ischemia $[1,2]$. Postconditioning (PostC), i.e. rapid, repeated cycles of ischemia and reperfusion before full reperfusion, exerts

Stine Falsig Pedersen, Ph.D

Dept. of Biology, University of Copenhagen

13, Universitetsparken, DK-2100 Copenhagen (Denmark)

Tel. +45 35321546/+45 20991555, Fax +45 35321567

E-Mail sfpedersen@bio.ku.dk 
a considerable, protective effect against reperfusion injury [3-5] under certain conditions and has been shown to reduce myocardial infarct size in vivo and in vitro [3]. Despite substantial advances in recent years, the mechanisms through which PostC exerts its protective effects are still incompletely understood $[3,6]$.

Cardiac $\mathrm{pH}$ homeostasis is severely compromised by ischemia: intracellular $\mathrm{pH}\left(\mathrm{pH}_{\mathrm{i}}\right)$ can decline by about $0.5 \mathrm{pH}$ units within the first $5 \mathrm{~min}$, and extracellular $\mathrm{pH}$ $\left(\mathrm{pH}_{\mathrm{o}}\right)$ can reach $\mathrm{pH}$ 6-6.5 [7]. Reduced $\mathrm{pH}_{\mathrm{i}}$ is protective to the heart through a number of different mechanisms, including inhibition of mitochondrial permeability transition pore (mPTP) formation, gap junction conductivity, several $\mathrm{Ca}^{2+}$-channels, $\mathrm{Na}^{+} / \mathrm{Ca}^{2+}$ exchange, activity of calpain and caspases, and other death effectors, and through reduced hypercontracture [e.g. [7, 8]. Upon reperfusion, cardiac $\mathrm{pH}_{\mathrm{i}}$ is rapidly normalized through wash out of protons and the activity of acid extruding transport proteins, allowing the opening of the $\mathrm{mPTP}$, and leading to $\mathrm{Na}^{+}$ and $\mathrm{Ca}^{2+}$ overload, hypercontracture, necrosis, and apoptosis [7,9]. Consequently, it has been proposed that a major mechanism through which PostC exerts its protective effect may be a delay in normalization of $\mathrm{pH}$ [8, 10-12]. In accordance with this view, staged reperfusion delayed the recovery of coronary venous blood $\mathrm{pH}$ (and thus presumably cardiomyocyte $\mathrm{pH}_{\mathrm{i}}$ ) in dogs exposed to coronary artery occlusion, and the protective effect of PostC was dependent on this delay [13]. Moreover, PostC delayed $\mathrm{pH}_{\mathrm{i}}$ recovery in isolated rat hearts in a manner correlating with the protective effect of the PostC treatment $[11,14]$, and in isolated rat and rabbit hearts, brief acidosis upon reperfusion was as protective as PostC $[10,11]$.

The major ion transporters contributing to normalization of $\mathrm{pH}_{\mathrm{i}}$ in the heart after an acid load are the $\mathrm{Na}^{+} / \mathrm{H}^{+}$exchanger $\mathrm{NHE} 1$ and $\mathrm{Na}^{+}-\mathrm{HCO}_{3}$ cotransporters (NBCs, [15]). Inhibition of NHE1 has been shown to exert protective effects in a large number of in vivo and in vitro experimental models of cardiac $\mathrm{I} / \mathrm{R}$ [see [7]. It has thus been speculated that the protective effect of PostC could be related to that of inhibiting NHE1 [8, 12]. However, this has never been directly addressed, although a role for cGMP/protein kinase $\mathrm{G}$ (PKG) mediated NHE1 inhibition was recently proposed [12]. Adding further complexity, NHE1 activity is anti-apoptotic in a number of settings $[16,17]$. These include, under some conditions, cardiac $\mathrm{I} / \mathrm{R}$, ostensibly because of a shift in the balance between the pro-survival and pro-death effects of NHE1 $[18,19]$. It is also notable that clinical trials have largely failed to demonstrate a protective effect of NHE1 inhibitors [20, 21], whereas PostC generally appears to be protective also in the clinical setting, although the number of such studies is still limited [22].

A central mechanism through which $\mathrm{pH}_{\mathrm{i}}-$ and hence $\mathrm{pH}_{\mathrm{i}}$ regulatory ion transporters - may influence survival after $\mathrm{I} / \mathrm{R}$ is via modulation of cellular signaling pathways regulating death-survival balance under these conditions. Well-established such mechanisms are the inhibition of mPTP formation by acidic $\mathrm{pH}_{\mathrm{i}}$ [23], and altered activity of stress-activated protein kinases such as p38 MAPK, JNK1/2, and protein kinase B (PKB)/Akt [24, 25]. Notably, p38 MAPK and JNK have previously been shown to exhibit marked $\mathrm{pH}_{\mathrm{i}}$-sensitivity, and Akt to be activated through NHE1-mediated recruitment of ezrinradixin-moesin (ERM) proteins [26-29].

Studies in cell culture model systems have been widely used to supplement and support ischemiareperfusion studies in intact heart and whole animal experiments. Many such studies have been carried out in one of the very few available immortalized cardiomyocyte lines with reasonable resemblance to adult cardiomyocytes, the HL-1 mouse atrial cardiomyocyte line [30]. However, while HL-1 cardiomyocytes bear many resemblances to adult cardiomyocytes [30], they also exhibit distinct differences from these cells with respect to e.g. mitochondrial organization and metabolism [31-33]. Also the contractile apparatus is not as organized as in the adult cardiomyocyte. This together could strongly impact on their response to $\mathrm{I} / \mathrm{R}$ - and postconditioning protocols. To our knowledge, no studies have yet evaluated their usefulness as a model for PostC.

The aim of the present study was to determine whether the protective effect of PostC can be mimicked by brief acidic reperfusion or by inhibition of NHE1, in intact perfused hearts compared to HL-1 cultured cardiomyocytes, and to assess the possible contribution of $\mathrm{pH}$ - and NHE1-sensitive regulation of stress kinases in reperfusion. We show that $15 \mathrm{~min}$ acidic treatment at the onset of reperfusion was at least as protective as PostC against I/R damage in intact rat hearts, whereas NHE1 inhibition was detrimental. In contrast, in HL-1 cardiomyocytes, necrotic or apoptotic death induced by $\mathrm{I} / \mathrm{R}$ in the presence of $\mathrm{HCO}_{3}{ }^{-}$was not attenuated by a 15 min acidic period at the onset of reperfusion. Finally, I/R in HL-1 cardiomyocytes increased the activity of the stress-activated kinases JNK1/2 and Akt. However, JNK $1 / 2$ and Akt activity was not regulated by acidic $\mathrm{pH}$ and NHE1 inhibition.

Andersen/Bentzen/Salling/Klingberg/Kanneworff/Grunnet/Pedersen 


\section{Materials and Methods}

\section{Reagents}

Unless otherwise stated, reagents were analytical grade and obtained from Sigma-Aldrich. 5' N-ethyl-N-isopropylamiloride (EIPA) was from Invitrogen and was dissolved in $\mathrm{ddH}_{2} \mathrm{O}$. Stock solutions of paraformaldehyde $(20 \% \mathrm{wt} / \mathrm{vol}$ in $\mathrm{ddH}_{2} \mathrm{O}$ ) were prepared fresh regularly and stored at $4{ }^{\circ} \mathrm{C}$. Antibodies against caspase-3 (detecting full-length caspase-3 $(35 \mathrm{kDa})$ and the $17 / 19 \mathrm{kDa}$ fragment resulting from cleavage at $\mathrm{Asp}^{175}$ ), poly (ADP-ribose) polymerase isoform 1 (PARP1) (detecting full length PARP1 $(116 \mathrm{kDa})$ as well as the $89 \mathrm{kDa}$ cleaved fragment), total JNK $1 / 2$, JNK $1 / 2$ phosphorylated at $\mathrm{Thr}^{183}$ and $\mathrm{Tyr}^{185}$, p38 MAPK, p38 MAPK phosphorylated at $\mathrm{Thr}^{180}$ and $\mathrm{Tyr}^{182}$, total Akt and Akt phosphorylated at Ser ${ }^{473}$ were from Cell Signaling Inc. 2,3,5-triphenyltetrazolium chloride (TTC) was from Sigma.

\section{Studies on isolatead perfused rat hearts}

Animals. Male Sprague-Dawley rats (Taconic, Denmark, body weight $250-450 \mathrm{~g}$ ) were used. The study protocol was approved by the Danish Committee on Research Animals, and all procedures were carried out in accordance with the Danish National Committee for Animal Studies guidelines.

Langendorff isolated perfused heart preparation. The isolated perfused heart experiments were carried out essentially as previously described [34]. The rats were anesthetized by subcutaneous injection of a mixture of midazolam $(2.5 \mathrm{mg} / \mathrm{kg})$, fluanisone $(2.5 \mathrm{mg} / \mathrm{kg})$, and fentanyl citrate $(0.08 \mathrm{mg} / \mathrm{kg})$, and heparin (1000 i.e. per kg) was injected intravenously to prevent coagulation. The trachea was intubated, allowing the lungs to be artificially ventilated prior to opening of the chest cavity. The heart was dissected free, the aorta cannulated, and retrograde coronary perfusion rapidly initiated, using a modified Krebs-Henseleit (KH) solution (in mM: $119.9 \mathrm{NaCl}, 3.3 \mathrm{KCl}, 25$ $\mathrm{NaHCO}_{3}, 11$ glucose, $1.2 \mathrm{MgSO}_{4}, 1.2 \mathrm{KH}_{2} \mathrm{PO}_{4}, 1.7 \mathrm{CaCl}_{2}$; prewarmed to $37^{\circ} \mathrm{C}$ and gassed with $5 \% \mathrm{CO}_{2} / 95 \% \mathrm{O}_{2}$ to maintain $\mathrm{pH}$ at 7.4). The hearts were mounted in a Langendorff perfusion apparatus (Hugo Sachs-Harvard Apparatus GmbH, Germany) and perfused at a constant pressure of $80 \mathrm{~mm} \mathrm{Hg}$. The left atrial appendix was removed and a latex balloon coupled to a pressure transducer was inserted into the left ventricle via the mitral valve to allow monitoring of left ventricular pressure and heart rate.

Experimental protocols. The rats were randomly assigned to one of 4 different treatment protocols (Fig. 1). In all cases, the perfused hearts were stabilized for $40 \mathrm{~min}$, followed by $35 \mathrm{~min}$ of global no-flow ischemia and $120 \mathrm{~min}$ of reperfusion. The 4 groups received the group-specific treatments immediately after ischemia, followed for all groups by $105 \mathrm{~min}$ reperfusion (i.e. a total reperfusion period of $120 \mathrm{~min}$ ) in $\mathrm{KH}$ solution at $\mathrm{pH} 7.4$. The treatment groups were: (i) $15 \mathrm{~min} 0.1 \%$ DMSO (vehicle ctrl); (ii) $15 \mathrm{~min} \mathrm{KH}$ solution $\mathrm{pH} 6.5\left(\mathrm{NaHCO}_{3}\right.$ concentration $1 \mathrm{mM}$, replaced by $\mathrm{NaCl}$ ); (iii) PostC, i.e. 6 cycles of $10 \mathrm{~s}$ reperfusion interspersed by $10 \mathrm{~s}$ of no-flow ischemia (6 $\mathrm{x} 10 \mathrm{~s} \mathrm{R} / \mathrm{I}$ ); and (iv) $15 \mathrm{~min}$ in $\mathrm{KH}$ solution containing $3 \mu \mathrm{M}$ of the NHE1 inhibitor EIPA. There were no significant differences

Cardioprotection by Acidic Reperfusion is not Mimicked by NHE1 Inhibition

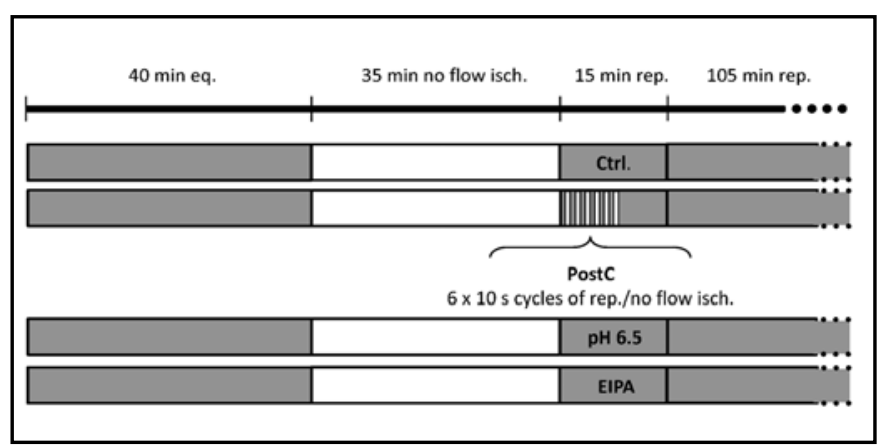

Fig. 1. Experimental protocols for the isolated perfused rat heart experiments. The basal setup comprised $40 \mathrm{~min}$ of stabilization (Eq), 35 min of global no-flow ischemia (isch.), and 120 min of reperfusion (rep.). The treatment groups differed only during the first 15 min of reperfusion. Ctrl: No treatment (DMSO vehicle); PostC: 6 x $10 \mathrm{~s} \mathrm{R/I}$ at the onset of reperfusion; $\mathrm{pH}$ 6.5: Acidic reperfusion ( $\mathrm{KH}$ solution adjusted with $\mathrm{HCO}_{3}^{-}$) during the first 15 min of reperfusion and; EIPA: Treatment with $3 \mu \mathrm{M}$ of the NHE1-inhibitor EIPA in the $\mathrm{KH}$-solution during the first $15 \mathrm{~min}$ of reperfusion.

between any of the treatment groups between the basal values of heart rate, aortic flow, left ventricular end diastolic pressure (LVeDP) and left ventricular developed pressure (LVDP).

Exclusion criteria. Hearts were excluded from analysis if they fulfilled one of the following criteria: (i) Inability to maintain a constant aortic pressure of $80 \mathrm{~mm} \mathrm{Hg}$ at a flow rate of 10-20 $\mathrm{ml} / \mathrm{min}$; (ii) sustained arrhythmia during the pre-ischemia stabilization phase; (iii) LVDP at the end of the stabilization phase of below 70 or above $150 \mathrm{mmHg}$; (iv) ventricular fibrillation at the onset of reperfusion which did not revert spontaneously within $10 \mathrm{~min}$ and could not be reverted by gentle mechanical stimulation. 5 hearts were excluded from analysis due to enduring arrhythmia after ischemia, and 8 hearts were excluded due to too high flow rate $(>20 \mathrm{ml} / \mathrm{min})$ in the stabilization period.

Assessment of heart functional parameters. The volume of the latex balloon was adjusted to achieve an LVeDP of 0-8 $\mathrm{mm} \mathrm{Hg}$ during the stabilization phase. All data were acquired at a sampling rate of $1 \mathrm{kHz}$ using a 16-channel PowerLab system (ADInstruments, UK) and analyzed using CHART 5 Pro software (ADInstruments, UK). LVDP was calculated as the difference between end-systolic and end-diastolic left ventricular pressure.

Determination of myocardial infarct size. The extent of infarct size was determined by 2,3,5-triphenyltetrazolium chloride (TTC) staining [35]. At the end of the $120 \mathrm{~min}$ of reperfusion the hearts were quickly detached, frozen at $-80^{\circ} \mathrm{C}$ for $15 \mathrm{~min}$, and cut into five $2 \mathrm{~mm}$ thick transverse sections. The slices were thawed, and incubated for $5 \mathrm{~min}$ at $37^{\circ} \mathrm{C}$ in TTC $\left(1 \%\right.$ in phosphate buffer $\left.\mathrm{pH} 7.4,37^{\circ} \mathrm{C}\right)$. The stained tissue slices were fixed in $4 \%$ formalin for $24 \mathrm{~h}$, washed three times in $\mathrm{ddH}_{2} \mathrm{O}$, weighed, and both sides of each slice were scanned at a resolution of 1200 dpi using a CANON Lide70 flatbed scanner. The area of infarct and the total area of the slice were quantified 
using Image-Tool 2.0 software (NIH, USA). The person conducting the measurements was blinded to the experimental groups. Total infarct size determined as the infarcted (white) area as a percentage of total muscle mass (representing total area, AAR) was calculated as the weighted mean of individual slice values, i.e.: $\left(\mathrm{AI}_{1} / \mathrm{AAR}_{1}\right) \times\left(\mathrm{W}_{1} / \mathrm{W}_{\text {total }}\right)+\left(\mathrm{AI}_{2} / \mathrm{AAR}_{2}\right) \times\left(\mathrm{W}_{2} /\right.$ $\left.\mathrm{W}_{\text {total }}\right) \ldots . .\left(\mathrm{AI}_{5} / \mathrm{AAR}_{5}\right) \times\left(\mathrm{W}_{5} / \mathrm{W}_{\text {total }}\right)$, where $\mathrm{AI}_{\mathrm{n}}$ is the area of infarct for the slice $(n), W_{n}$ is the weight of section $n$ and $W_{\text {total }}$ is the total weight of all five slices.

\section{Studies on HL-1 cardiomyocytes}

Cell culture. HL-1 mouse cardiomyocytes were a kind gift from Dr. W. Claycomb (Louisiana State University Health Sciences Center, New Orleans, LA), and were cultured as previously described [18, 30]. Briefly, non-contracting HL-1 cardiomyocytes were maintained in Claycomb medium supplemented with $0.1 \mathrm{mM}$ norepinephrine and 10\% FBS (all JRH Biosciences, Lenexa, Kansas), 2 mM L-glutamine, $100 \mathrm{U} /$ $\mathrm{ml}$ penicillin, and $100 \mu \mathrm{g} / \mathrm{ml}$ streptomycin (all Invitrogen) in 5\% $\mathrm{CO}_{2}$ at $37^{\circ} \mathrm{C}$ and $95 \%$ humidity. The cells were passaged every 3 days by trypsination (trypsin/EDTA, Invitrogen) and transferred to culture flasks coated with gelatin/fibronectin (Becton Dickinson). All experiments were performed on confluent cells.

Simulated ischemia-reperfusion protocol, HL-1 cells. I/ $\mathrm{R}$ was simulated essentially as previously described [18]. Confluent HL-1 cells were placed in a closed incubator/ workspace system (XVIVO G300C, BioSpherix, Redfield, NY) preset to $37^{\circ} \mathrm{C}, 95 \%$ humidity, 21 (normoxia/reperfusion) or $0.5 \%$ (simulated ischemia, replacement with $\left.\mathrm{N}_{2}\right) \mathrm{O}_{2}$, and $5 \% \mathrm{CO}_{2}\left(\mathrm{HCO}_{3}^{-}\right.$ -buffered solutions). The $\mathrm{HCO}_{3}^{-}$buffered Ringer solution (HR) contained (in mM) $1.25 \mathrm{CaCl}_{2}, 1 \mathrm{MgCl}_{2}, 137 \mathrm{NaCl}, 6 \mathrm{KCl}, 10$ glucose, and $0.9 \mathrm{NaH}_{2} \mathrm{PO}_{4}$, and 25 or $1 \mathrm{mM}$ of $\mathrm{NaCl}$ was replaced by $\mathrm{NaHCO}_{3}$ for $\mathrm{pH} 7.4$ and $\mathrm{pH} 6.0$ solutions, respectively. Simulated ischemia was carried out in Ischemia Ringer solution, containing (in mM) $1.25 \mathrm{CaCl}_{2}, 1 \mathrm{MgCl}_{2}, 119 \mathrm{NaCl}, 1 \mathrm{NaHCO}_{3}, 8$ $\mathrm{KCl}, 20 \mathrm{Na}$-lactate, $0.9 \mathrm{NaH}_{2} \mathrm{PO}_{4}$, pH 6.0. HL-1 cells were exposed to simulated ischemia for $5 \mathrm{~h}$, followed by $2 \mathrm{~h}$ of simulated reperfusion $+/$ - acidic reperfusion during the first $15 \mathrm{~min}$ of the reperfusion period, or to normoxia.

SDS gel electrophoresis and immunoblotting. Immunoblotting was carried out essentially as previously described [18]. Briefly, HL-1 cells grown to confluence in gelatin/ fibronectin-coated Petri dishes were washed twice in ice-cold PBS (in mM: $137 \mathrm{NaCl}, 2.7 \mathrm{KCl}, 8.1 \mathrm{Na}_{2} \mathrm{HPO} 4,1.7 \mathrm{KH}_{2} \mathrm{HPO}_{4}$ ), lysed in lysis buffer ( $1 \%$ SDS, $10 \mathrm{mM}$ Tris pH 7.4, $1 \mu \mathrm{M} \mathrm{NaVO}_{4}$ and Complete Mini protease-inhibitor cocktail (Roche, Denmark)), homogenized through a 27-gauge syringe, and cleared by centrifugation ( $5 \mathrm{~min}, 20,000 \mathrm{~g}$ ). Protein content was determined (DC Protein Assay, Bio-Rad, Copenhagen, Denmark), lysates with equal amounts of protein were prepared in LDS NuPAGE sample buffer with $50 \mathrm{mM}$ DTT, resolved by SDS-PAGE on $10 \%$ NuPage Bis-Tris gels in NOVEX electrophoresis chambers and transferred to nitrocellulose membranes (Invitrogen). After Ponceau staining to confirm equal loading, membranes were incubated overnight at $4{ }^{\circ} \mathrm{C}$ in blocking buffer $(120 \mathrm{mM} \mathrm{NaCl}, 10 \mathrm{mM}$ Tris $\mathrm{pH} 7.5,0.1 \%$ Tween $20,5 \%$ nonfat dry milk), for $2 \mathrm{~h}$ at room temperature with primary antibody diluted in blocking buffer, washed in TBST (120 mM $\mathrm{NaCl}, 10 \mathrm{mM}$ Tris $\mathrm{pH} 7.5$, and $0.1 \%$ Tween 20 ), incubated with alkaline phosphatase-conjugated secondary antibody, washed, and immunolabeling detected by BCIP/NBT (KPL, Gaithersburg, MD). Densitometric analysis of the blots was performed using UN-SCAN-IT software (Silk Scientific, Orem, UT).

Estimates of necrotic and apoptotic cell death. Necrotic cell death in HL-1 mouse cardiomyocytes was estimated as release of the cytosolic housekeeping enzyme glucose 6-phosphate dehydrogenase (G6PD) to the surrounding medium due to compromised sarcolemmal integrity. The Vybrant Cytotoxicity Assay Kit (Molecular Probes) was used, following the manufacturer's directions. The activity of G6PD released from necrotic cells reduces $\mathrm{NADP}^{+}$to NADPH followed by reduction of resazurin to resorufin. Resorufin emits at $587 \mathrm{~nm}$ after excitation at $563 \mathrm{~nm}$. The signal is proportional to the amount of released G6PD and correlating to the number of necrotic cells in the sample. For these experiments, HL-1 cardiomyocytes were grown to confluence in black gelatine/fibronectin coated 96 well plates. The experiments were performed in $\mathrm{HCO}_{3}^{-}$buffered Ringer solutions. In these experiments, changes in Ringer composition were made by addition of modified Ringer solutions, and lactate during simulated ischemia omitted, as this was necessary to avoid aspiration steps. Fluorescence was detected on a FLOUstar OPTIMA microplate reader (BMG Labtechnologies) ex/em 544/590 nm. All estimates of necrotic cell death are relative to samples of fully lysed HL-1 cardiomyocytes.

Induction of apoptotic cell death pathways was assessed by monitoring cleavage of caspase- 3 and PARP1. This was done by western blotting as above, using antibodies recognizing both full-length and cleaved forms of these proteins (35 and $17 \mathrm{kDa}$ procaspase-3 and caspase-3; 116 and $89 \mathrm{kDa}$ for full-length and cleaved PARP) (both Cell Signaling Technology). Apoptotic cell death in HL-1 mouse cardiomyocytes was also measured as chromatin condensation. Cells were grown in small gelatin/fibronectin coated Petri dishes $\left(\sim 10 \mathrm{~cm}^{2}\right)$ to an approximated monolayer. The experiments were performed in $\mathrm{HCO}_{3}$-buffered Ringer solution. After stimulation the DNAbinding component Hoechst 33258 (Sigma-Aldrich) was added to a final concentration of $25 \mu \mathrm{g} / \mathrm{ml}$ for the last $20 \mathrm{~min}$ of each protocol setup. Hoechst 33258 in a DNA-binding complex emits fluorescence at $465 \mathrm{~nm}$ after excitation at $356 \mathrm{~nm}$ and was detected using the 20x/0.6 NA objective of a Leica DM-IRB/E microscope (Leica, Heidelberg, Germany). Cells in five randomly chosen areas of each sample were counted. Apoptotic cells with condensed chromatin appear brighter compared to cells with non-condensed chromatin.

\section{Statistical analysis}

Data are shown as representative individual experiments or as mean with standard error of the mean (s.e.m.) error bars. Unless otherwise indicated, significance was tested using oneway ANOVA test followed by Tukey Kramer post-hoc Multiple Comparison test. For bootstrap analysis of Langendorff data, mean differences $\left(\mathrm{AUC}_{0-120 \mathrm{~min}}\right)$ and $95 \%$ confidence intervals were computed via bootstrapping 10.000 resamples in pairwise comparisons. A priori four pairwise comparisons were selected

Andersen/Bentzen/Salling/Klingberg/Kanneworff/Grunnet/Pedersen 


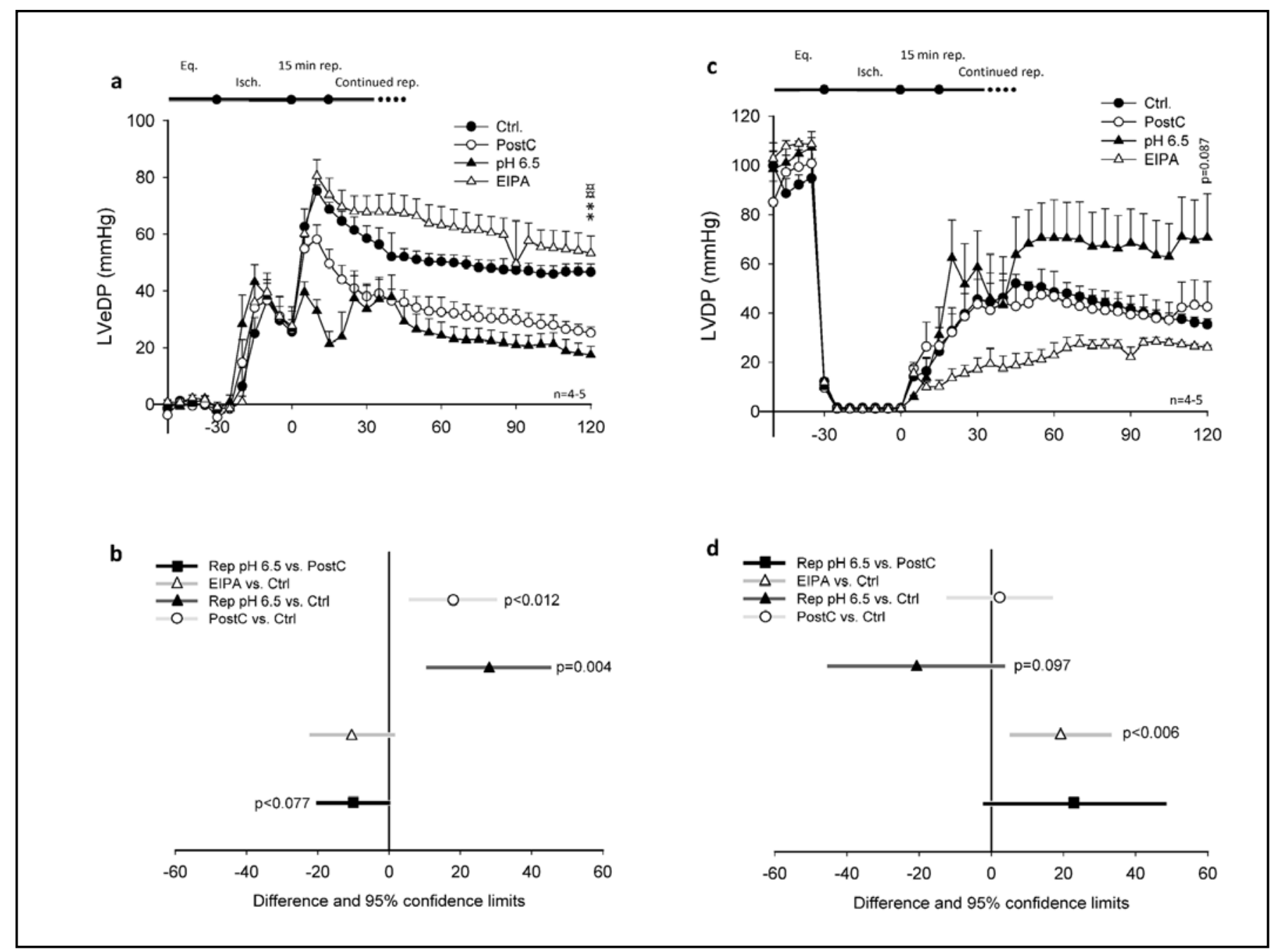

Fig. 2. PostC and acidic reperfusion in isolated perfused rat hearts is protective against $I / R$-induced deterioration of heart functional parameters whereas EIPA is detrimental. Hearts were stabilized for $40 \mathrm{~min}$ (Eq), followed by $35 \mathrm{~min}$ of global no-flow ischemia (isch.), and 120 min of reperfusion (rep.). Ctrl (O): No treatment (DMSO vehicle); PostC (O): 6 x $10 \mathrm{~s} \mathrm{R/I} \mathrm{at} \mathrm{the} \mathrm{onset} \mathrm{of}$ reperfusion; $\mathrm{pH} 6.5(\boldsymbol{\Delta})$ : Acidic reperfusion during the first $15 \mathrm{~min}$ of reperfusion and; EIPA $(\triangle)$ : Treatment with $3 \mu \mathrm{M}$ of the NHE1-inhibitor EIPA during the first 15 min of reperfusion. Shown are the effects of the different treatments on a: LVeDP, and c: LVDP. Each point represents the mean + SEM of the preceding 5 min of recording. $n=4-5$ per group. One-way Anova was performed on the final datapoint (i.e. $115-120 \mathrm{~min}$ of reperfusion, $\mathrm{n}=3-4)$ ) ${ }^{* *} p<0.01$, Rep. $\mathrm{pH} 6.5$ compared to control conditions; co $p<0.01$, PostC compared to control conditions, $\mathrm{p}=0.087$, Rep. $\mathrm{pH} 6.5$ compared to control conditions. b, d): Assesment of difference between chosen treatment groups over the whole reperfusion period was performed by bootstrap analysis.

for bootstrap analysis: Control against all treatments and acidic reperfusion against PostC. The Bootstrap simulations were programmed in $\mathrm{SAS} \AA$ rel. 9.1.3.

\section{Results}

PostC and brief acidic reperfusion both exert protective effects on heart functional parameters and infarct size, whereas NHE1 inhibition is detrimental

The treatment groups are outlined in Fig. 1. In control

Cardioprotection by Acidic Reperfusion is not Mimicked by NHE1 Inhibition hearts, $35 \mathrm{~min}$ of no-flow ischemia followed by $120 \mathrm{~min}$ of reperfusion strongly attenuated cardiac function and the ability to obtain proper relaxation in the diastolic interval, addressed as left ventricular end-diastolic pressure (LVeDP) was markedly reduced reaching a maximum of about $70 \mathrm{~mm} \mathrm{Hg}$, recovering to about 40 $\mathrm{mm} \mathrm{Hg}$ after $120 \mathrm{~min}$ of reperfusion (Fig. 2a). The ability to obtain appropriate contractile force was addressed from left ventricular developed pressure (LVDP) and was about $90 \mathrm{~mm} \mathrm{Hg}$ prior to ischemia, recovering to about $40 \mathrm{~mm} \mathrm{Hg}$ at the end of the reperfusion period (Fig. 2c);

Cell Physiol Biochem 2011;28:13-24 
Fig. 3. Effect of PostC and acidic reperfusion on infarct size after I/R. Hearts were stabilized for $40 \mathrm{~min}(\mathrm{Eq})$, followed by 35 min of global no-flow ischemia (isch.), and $120 \mathrm{~min}$ of reperfusion (rep.). Ctrl: No treatment (DMSO vehicle); PostC: 6 $\mathrm{x} 10 \mathrm{~s} \mathrm{R} / \mathrm{I}$ at the onset of reperfusion; $\mathrm{pH}$ 6.5: Acidic reperfusion during the first $15 \mathrm{~min}$ of reperfusion and; EIPA: Treatment with $3 \mu \mathrm{M}$ of the NHE1-inhibitor EIPA during the first $15 \mathrm{~min}$ of reperfusion. After this protocol, hearts were stained with TTC to demarcate infarcted and viable areas. a. Representative images of slices of rat hearts from the different treatment groups are shown. Red color represents viable tissue while white color represents the infarct: tissue damaged by necrotic cell death. b. Quantification of images as in A. Quantification was carried out blinded, using ImageJ $1.42 \mathrm{NIH}$ software, as described in Experimental Procedures. Data are from 3-4 independent experiments for each group. One-way ANOVA was performed.

and the flow rate, which was about $12 \mathrm{ml} / \mathrm{min}$ prior to ischemia, initially recovered upon reperfusion but then slowly declined (data not shown), reflecting extensive myocardial damage. In congruence with the functional data, TCC staining showed that about $40 \%$ of total muscle mass of the control hearts was infarcted at the end of the reperfusion period (Fig. 3). The data are summarized for all treatment groups in Table 1.

The effects of PostC and acidic reperfusion were tested using a PostC protocol of $6 \times 10 \mathrm{~s} / 10 \mathrm{~s} \mathrm{R} / \mathrm{I}$ at the onset of reperfusion, or exposure of the hearts to $\mathrm{KH}$ solution of $\mathrm{pH} 6.5$ for the first 15 min of reperfusion, respectively. As seen in Fig. 2a, the LVeDP during reperfusion was significantly reduced by the two treatments, both when assessed for the duration of the reperfusion period (bootstrap analysis, Fig. 2b) and when analyzed for the $120 \mathrm{~min}$ time point (ANOVA). Interestingly the bootstrap analysis showed a near significant difference between the PostC and the acidic reperfusion treatment groups $(\mathrm{p}<0.077)$. This points to a more pronounced effect of acidic reperfusion compared to that of PostC and was further supported by the fact that LVeDP in the pH 6.5-treated and not in the PostC hearts was significantly lower than that of control hearts already within the first $5 \mathrm{~min}$ of the acidic treatment phase, and remained so throughout the $15 \mathrm{~min}$. In the 5-10 and 10-15 min periods, it was also significantly different from that of PostC hearts (ANOVA). Thus, the protective effect is pronounced, and greater than that of PostC, within a few minutes of acidic exposure. The effects on LVDP were less marked but there was a non-significant tendency for improvement at least after acidic reperfusion (Fig 2c-d). Also there were no significant changes in the

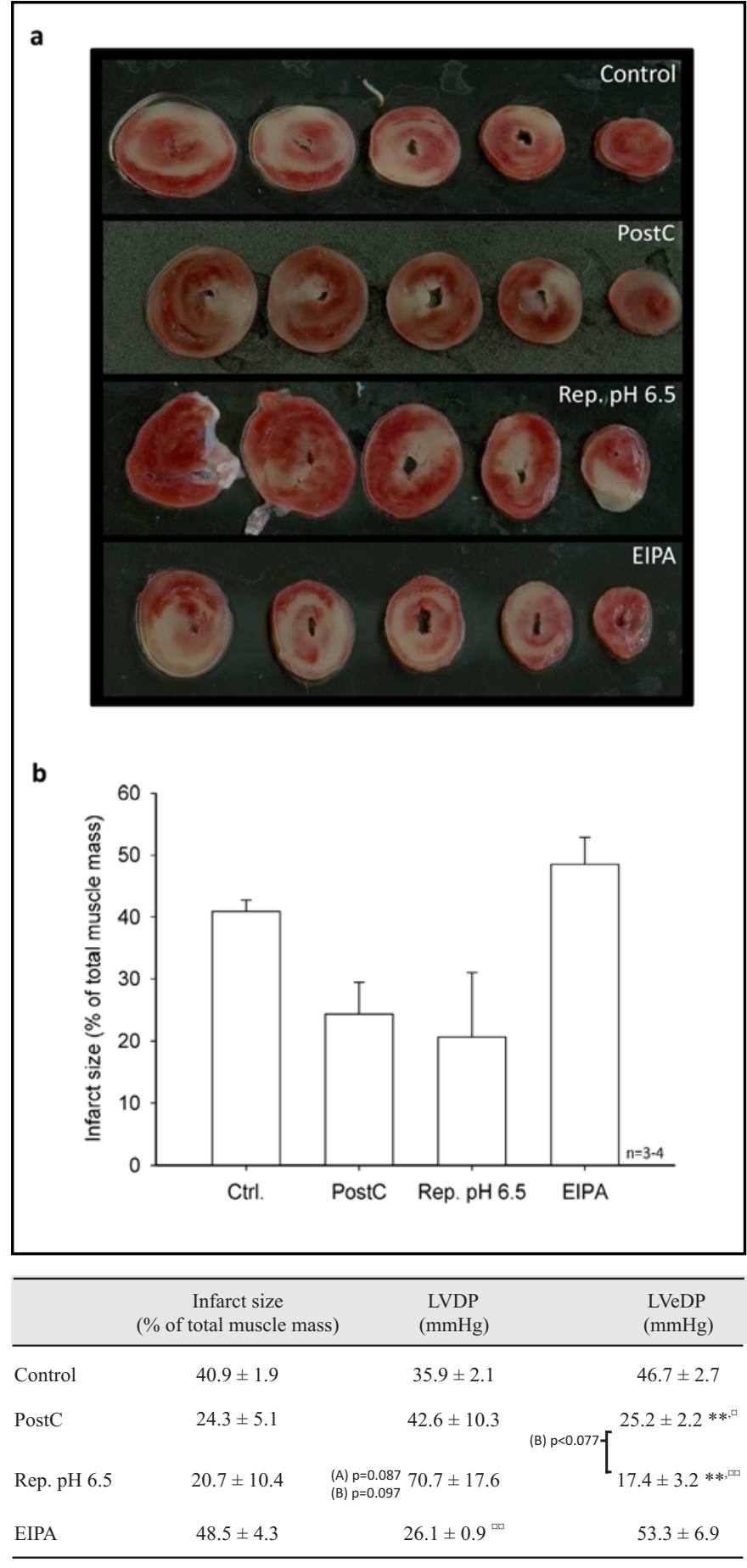

Table 1. Heart functional parameters and infarct size. Summarized data from the isolated perfused heart experiments. Infarct size is expressed as a percentage of total muscle mass. Significance was tested by one-way ANOVA, for functionality data on the datapoint representing 115-120 min of reperfusion (A), or via bootstrap analysis (B). ${ }^{* *} \mathrm{p}<0.01$, compared to control conditions by (A);,$p<<0.05$,, $0 p<0.01$, compared to control conditions by (B); $\mathrm{p}=0.087$ and $\mathrm{p}=0.097$ compared to control conditions. $\mathrm{n}=3-4$.

flow rate, but a tendency towards a slightly lower initial recovery in the acidic group was observed (data not

Andersen/Bentzen/Salling/Klingberg/Kanneworff/Grunnet/Pedersen 
Fig. 4. Effect of simulated ischemia and neutral or acidic reperfusion on necrotic and apoptotic cell death mechanisms in HL-1 cardiomyocytes. Cells were exposed to $5 \mathrm{~h}$ of simulated ischemia followed by 15 min of acidic $\left(\mathrm{pH}_{\mathrm{o}} 6.0\right)$ or $\mathrm{pH}$-neutral $\left(\mathrm{pH}_{\mathrm{o}}\right.$ 7.4) reperfusion before another $1 \mathrm{~h} 45 \mathrm{~min}$ of $\mathrm{pH}$-neutral reperfusion. a: Necrotic cell death was measured as glucose 6-phosphate dehydrogenase (G6PD) release as described in Experimental Procedures. Data are shown as fractions of G6PD release relative to fully lysed cells and are means + SEM of 8 experiments. Student's t-test was performed. $* * p<0.01$ $* * * p<0.001$, indicates significant difference from that in parallel normoxic controls. b: Cells were treated with or without $5 \mu \mathrm{M}$ EIPA to inhibit NHE1 during reperfusion. Subsequently, cells were lysed, and death effector activity was determined by Western blotting as cleavage of $\mathrm{b} 1$ : procaspase and $\mathrm{b} 2$ : full length PARP. Top: representative Western blots. Bottom: summary data for 7 experiments, showing the abundance of the cleaved relative to the non-cleaved forms, normalized to $7 \mathrm{~h}$ normoxic control (means + SEM). Student's t-test was performed. $* p<0.05$ and $* * p<0.01$, indicates significant difference from that in parallel normoxic controls.

shown). In accordance with these protective effects, both PostC and acidic reperfusion were associated with an about $50 \%$ reduction of the infarct size (Fig. 3, Table 1). We next asked whether these protective effects of PostC and acidic reperfusion could be mimicked by inhibition of NHE1. As seen in Fig. 2c-d, in contrast to these treatments, the NHE1 inhibitor EIPA significantly decreased LVDP and also a modest increase of LVeDP was detected (Fig. 2a), whereas the flow rate was unaffected (data not shown). Infarct area was increased by $20 \%$ to $48.5 \pm 4.3 \%$ compared to $40.9 \pm 1.9 \%$ in controls (Fig. 3, Table 1).

Thus, in isolated, perfused rat hearts, mechanical PostC and 15 min of acidic ( $\mathrm{pH}$ 6.5) reperfusion were protective against $\mathrm{I} / \mathrm{R}$ damage, protection with acidic reperfusion consistently tending to be greater than with PostC for infarct size, LVDP, and LVeDP. In contrast, inhibition of NHE1 was detrimental to heart functional parameters.

Brief acidic reperfusion is not protective against cellular reperfusion damage in cultured $H L-1$ cardiomyocytes in the presence of $\mathrm{HCO}_{3}^{-}$

To assess the usefulness of the cultured HL-1 cardiomyocytes as a cellular model for acidic postconditioning we exposed these cells to a simulated I/ $\mathrm{R}$ protocol (hereafter: $\mathrm{I} / \mathrm{R}$ ) mimicking as closely as possible the conditions in the perfused intact hearts. The

Cardioprotection by Acidic Reperfusion is not Mimicked by NHE1 Inhibition

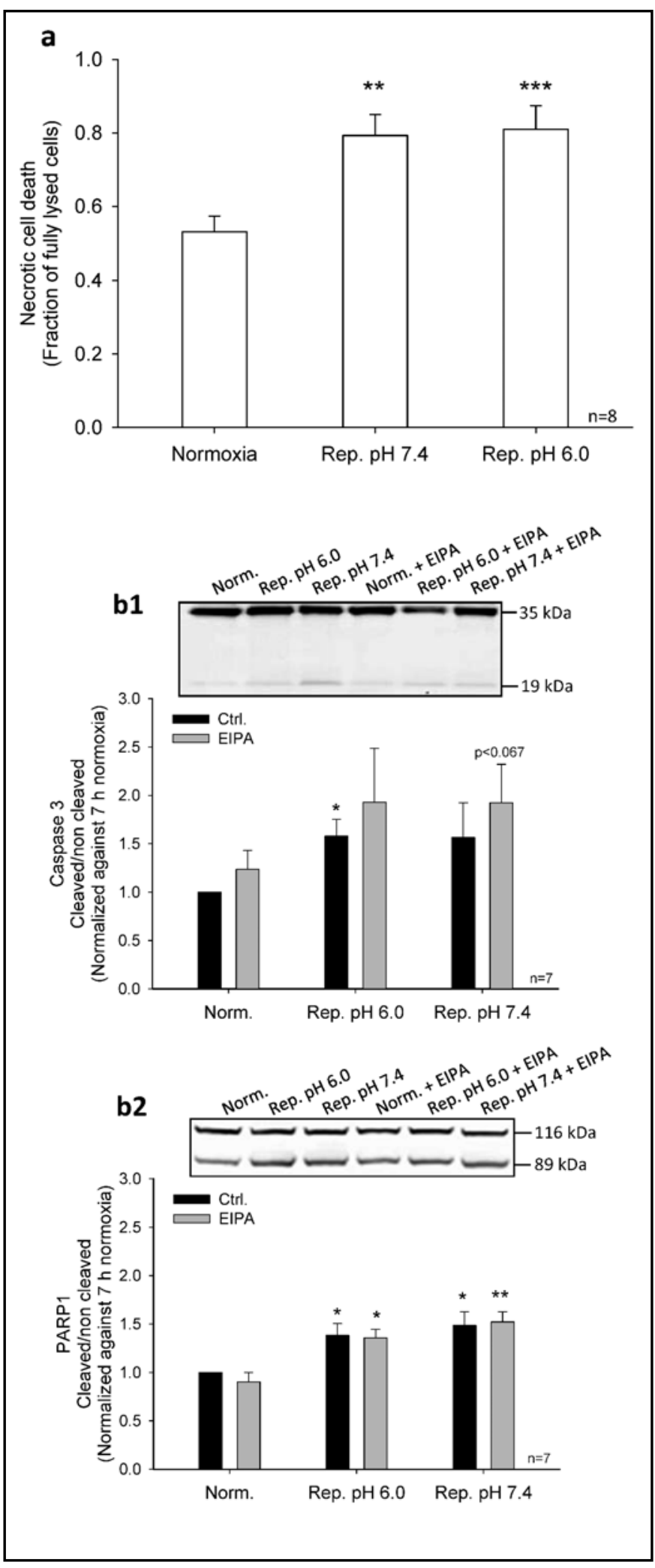

cardiomyocytes were exposed to ischemia $\left(0.5 \% \mathrm{O}_{2}, 5 \%\right.$ $\mathrm{CO}_{2}$, simulated ischemia Ringer) for $5 \mathrm{~h}$, followed by $2 \mathrm{~h}$ of reperfusion at $\mathrm{pH}$ 7.4. The first $15 \mathrm{~min}$ of reperfusion the HR pH was $\mathrm{pH} 7.4$ (ctrl.), or was reduced to $\mathrm{pH} 6.0$ (acidic reperfusion), or contained the NHE1 inhibitor.

Cell Physiol Biochem 2011;28:13-24 
Fig. 5. Simulated ischemia and reperfusion induces $\mathrm{pH}$ and NHE1-independent activation of Akt and $\mathrm{JNK} 1 / 2$ but not of p38 MAPK in HL1 cardiomyocytes. Cells were exposed to $5 \mathrm{~h}$ simulated ischemia followed by $15 \mathrm{~min}$ of acidic $\left(\mathrm{pH}_{\mathrm{o}} 6.0\right)$ or $\mathrm{pH}$ neutral $\left(\mathrm{pH}_{\mathrm{o}}\right.$ 7.4) reperfusion before another $1 \mathrm{~h} 45 \mathrm{~min}$ of pH-neutral reperfusion. During reperfusion cells were treated with or without $5 \mu \mathrm{M}$ EIPA. Cells were lysed and kinase activation assessed by Western blotting using phospho- and total antibodies against a: Akt, b: JNK1, c JNK2, and d: p38 MAPK. Top a-d: representative Western blots. Bottom a-d: summary data for 3-4 experiments per condition, showing phospho- relative to total kinase abundance, normalized to normoxic control (means + SEM). Student's t-test was performed. $* p<0.05$ and $* * p$ $<0.01$, indicates a significant difference from that in parallel normoxic controls.
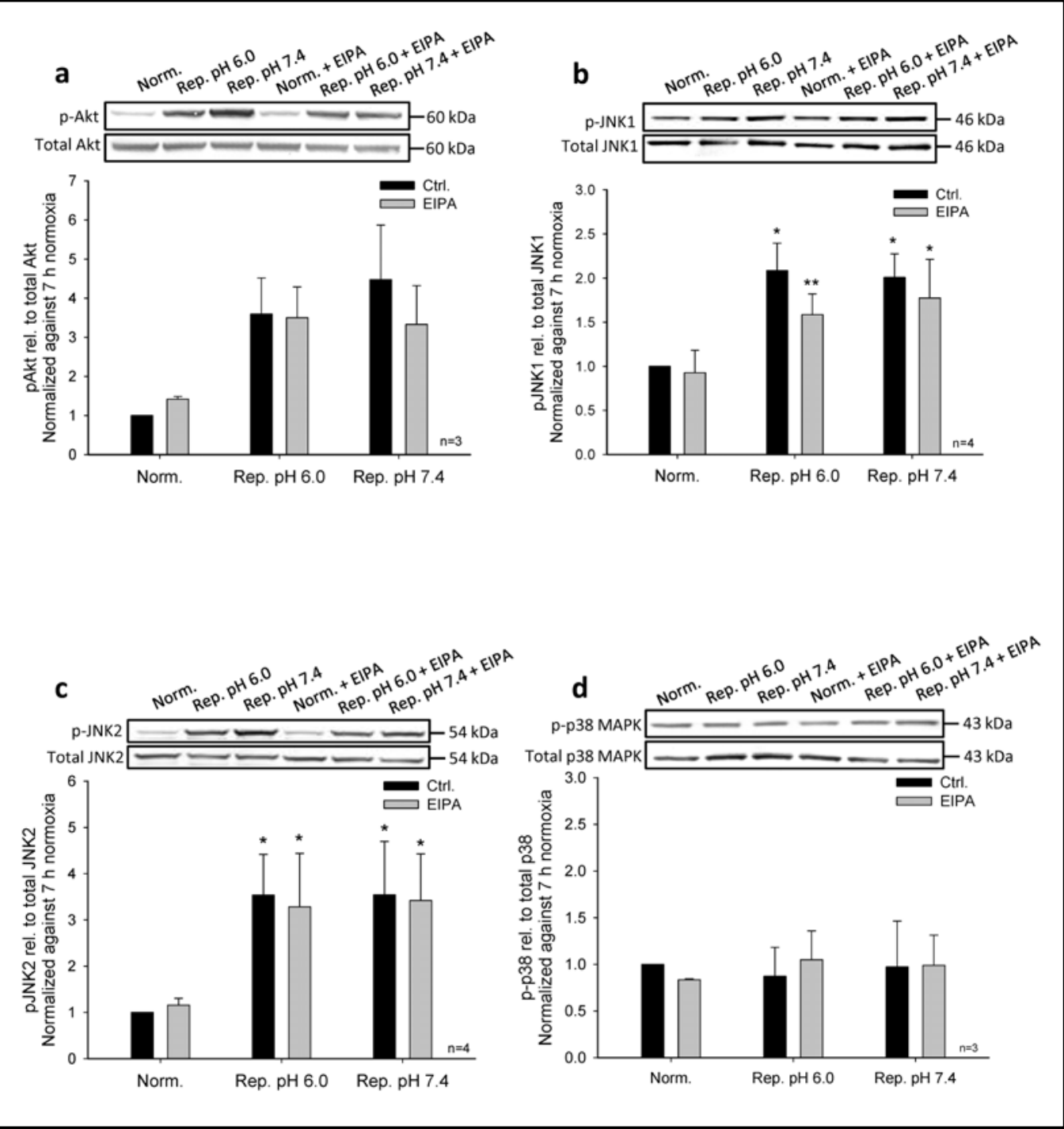

Normoxic controls were carried out in parallel, in HR Ringer $\mathrm{pH}$ 7.4.

Necrotic HL-1 cell death, assessed as G6PD release to the surrounding medium, was significantly increased by I/R (Fig. 4a) but 15 min acidic reperfusion was not protective against the $\mathrm{I} / \mathrm{R}$-induced necrotic cell death. Induction of apoptotic cell death pathways was assessed by monitoring cleavage of caspase- 3 from pro-caspase to active form, and PARP1 from its $116 \mathrm{kDa}$ full length form to the $89 \mathrm{kDa}$ fragment. As seen, both caspase-3and PARP1 cleavage were increased by I/R (Fig. 4b). Similar to what was seen for necrotic cell death, $15 \mathrm{~min}$ acidic reperfusion could not protect HL-1 against caspase3- and PARP1 cleavage. The lack of protective effect of brief acidic reperfusion was verified using chromatin condensation assays ( $\mathrm{n}=4$, data not shown). The presence of EIPA in the first $15 \mathrm{~min}$ of reperfusion to inhibit NHE1 had no significant effect on I/R-induced caspase-3- and PARP1 cleavage, suggesting that NHE1 activity does not modulate apoptotic death of HL-1 cardiomyocytes under these conditions.

$I / R$ in cultured HL-1 cardiomyocytes is associated with $\mathrm{pH}$-independent activation of Akt and JNK, but not of $p 38$ MAPK

The divergent effects of acidic postconditioning on death between whole hearts and cultured cardiomyocytes could reflect the absence of hypercontracture-related damage in HL-1 cells, but also differences in upstream signaling can play a role. We evaluated the total and active, phosphorylated levels of Jnk1/2, p38 MAPK, and Akt after I/R with or without $15 \mathrm{~min}$ at $\mathrm{pH} 6.0$ at onset of reperfusion, and in parallel normoxic controls in HL-1 cardiomyocytes. As noted above, these kinases have been assigned major roles in control of cell death/survival balance after I/R $[6,24,36]$, and have been reported to be regulated by $\mathrm{pH}_{\mathrm{i}}(\mathrm{JNK}, \mathrm{p} 38 \mathrm{MAPK})$ and by NHE1 (Akt). Furthermore, altered activity of these kinases during

Andersen/Bentzen/Salling/Klingberg/Kanneworff/Grunnet/Pedersen 
postconditioning procedures has been reported [37, 38]. The activity of Akt was increased by $\mathrm{I} / \mathrm{R}$, and this was unaffected by brief acidic reperfusion, in the absence or presence of EIPA (Fig. 5a). Both JNK1 and JNK2 activity was significantly increased by $\mathrm{I} / \mathrm{R}$, in a manner unaffected by reperfusion $\mathrm{pH}$ or EIPA (Fig. 5b-c). The activity of p38 MAPK was not affected by $\mathrm{I} / \mathrm{R}$ under any of the conditions tested (Fig. 5d). Thus, Akt and JNK1/ 2 activity is increased in HL-1 cardiomyocytes after I/R, and this activation is insensitive to brief acidic reperfusion and to NHE1 inhibition. In contrast, under these conditions, there was no net effect of I/R on p38 MAPK activity.

\section{Discussion}

Although PostC has been shown to have, under some conditions, strong protective effects against reperfusion injury after cardiac ischemia, the mechanisms involved are incompletely understood. Recent studies have suggested a role for delayed recovery of $\mathrm{pH}_{\mathrm{i}}$ in the protective effect of PostC $[8,11,12,39]$. Inhibition of NHE1, which at least in some cases will also lead to delayed $\mathrm{pH}_{\mathrm{i}}$ recovery after ischemia, is similarly strongly protective against reperfusion injury in some models of cardiac ischemia [7]. A role for NHE1 inhibition by the cGMP/PKG pathway in PostC was recently suggested, albeit not experimentally verified in the intact heart [12].

Here, we therefore asked the central question of whether PostC and acidic $\mathrm{pH}_{\mathrm{o}}$ (which will also lead to a reduction of $\mathrm{pH}_{\mathrm{i}}$ ) exerts similar protective effects against $\mathrm{I} / \mathrm{R}$ damage in Langendorff perfused hearts, and whether these effects can be mimicked by inhibiting NHE1. For statistical analysis of the Langendorff data we employed both conventional one-way ANOVA with Tukey-Kramer post-test at the $120 \mathrm{~min}$ time point, and the bootstrapping technique to evaluate for possible differences over the entire $120 \mathrm{~min}$ reperfusion range. Notably, $15 \mathrm{~min}$ exposure to $\mathrm{pH} 6.5$ followed by normal reperfusion at neutral $\mathrm{pH}$ exerted a protective effect in this model that consistently tended to be more pronounced than that of ischemic PostC. This was particularly marked for LVeDP, where we observed a near-significant difference $(p<0.077$, bootstrap analysis) between the two treatments. Also maximal systolic pressure (LVDP+LVeDP; data not shown) was significantly lower after ischemic postconditioning compared to acidic reperfusion $(t$-test, $\mathrm{p}$ $<0.05)$. We furthermore observed a numerical $15 \%$ decrease in maximal systolic pressure after ischemic postconditioning compared to control hearts. This

Cardioprotection by Acidic Reperfusion is not Mimicked by NHE1 Inhibition demonstrates that the mechanisms accounting for the cardioprotective effects of acidic reperfusion differ from those of ischemic postconditioning and also that there might be detrimental side effects of the procedure of mechanical ischemic postconditioning. Notably, already during the first few minutes of the 15 min treatment phase, LVeDP in the $\mathrm{pH}$ 6.5-treated hearts was significantly lower than that of control hearts. This demonstrates an almost immediate protective effect of the acidic exposure that was not seen for the PostC protocol. Future studies should address the marked protective effect of brief acidic reperfusion, and the mechanisms by which it might partially differ from that of PostC. Importantly, in contrast to the protective effect of acidic reperfusion and PostC, 15 min exposure to EIPA augmented reperfusion damage. A pertinent conclusion of this study therefore is that, in the perfused heart model employed, the protective effects of PostC and of acidic reperfusion do not reflect inhibition of NHE1 and cannot be mimicked by inhibiting this transporter. Moreover acidic reperfusion is more protective than PostC by increasing the improvements of the functional recovery of the hearts.

This study differs from other whole perfused heart studies that have shown a protective effect of EIPA primarily in the timing and duration of the exposure to EIPA, with most (albeit not all, e.g. [40]) other studies having EIPA present in the ischemic phase [see 7]. It is interesting, however that the present findings agree well with the results of clinical trials, which have failed to show a protective effect of the NHE1 inhibitor cariporide [20, 21]. In contrast, PostC has generally been found to be protective in clinical trials, although only a few such trials exist at this point [22]. It has been suggested that NHE1 activity is reduced or absent during ischemia per se, reflecting ATP-depletion and reduced $\mathrm{pH}_{\mathrm{o}}$ [see 7]. However, both parameters recover rapidly during early reperfusion, restoring NHE1 activity [7, 41]. Hence, it is highly unlikely that the lack of protective effect of NHE1 inhibition during reperfusion reflects that NHE1 is not active in this phase. It is also important in this regard that inhibition of NHE1 during I/R in fact does not necessarily lead to a delay in $\mathrm{pH}_{\mathrm{i}}$ recovery $[7,41]$. This likely reflects both the increased requirement for $\mathrm{Na}^{+} / \mathrm{K}^{+}$ATPase activity and hence $\left(\mathrm{H}^{+}\right.$producing) ATP consumption resulting from NHE1 activity, and contributions from other $\mathrm{H}^{+}$extruding transporters, such as $\mathrm{Na}^{+}, \mathrm{HCO}_{3}^{-}$ cotransporters, which play a major role in $\mathrm{pH}_{\mathrm{i}}$ regulation in the heart [see 7, 15].

Our study has some limitations. Firstly, we cannot exclude that in other perfused heart models, such as a 
working heart model, or in other species, the balance between protective and detrimental effects of NHE1 inhibition would be different, resulting in a net protective role of NHE1 inhibition. Second, although we used low concentrations of EIPA (3-5 $\mu \mathrm{M})$, we cannot rule out that non-NHE1 specific effects of EIPA might contribute to our findings, as proposed in studies of NHE1 inhibitors added during the ischemia phase per se [42]. Reported non-NHE1 effects of NHE1 inhibitors include inhibition of $\mathrm{Na}^{+} / \mathrm{Ca}^{2+}$ exchange (NCX) and cardiac $\mathrm{Na}^{+}$channels, as well as mitochondrial effects. The former, however, would be expected to exert protective rather than detrimental effects [see [7] and hence are unlikely to explain the effects observed in the present study. The mitochondrial effects have been reported for both EIPA and the more NHE1-specific cariporide [43, 44], indicating that cariporide would not offer much advantage in terms of possible side effects, and also, in our view, hinting that such suggested non-NHE1 effects may in fact be NHE1-related.

To map the mechanisms leading to the protection by PostC and potentially exploit these in a clinically relevant form, it is necessary to understand how PostC treatments affect the individual cardiomyocyte. HL-1 atrial cardiomyocytes in many ways resemble adult cardiomyocytes [30], and are a convenient and widely used tool for cellular level analysis of cardiac function. However, both contracting and non-contracting versions of these cells exhibit a number of differences from adult cardiomyocytes that could compromise their usefulness for studies of PostC. These include major differences in mitochondrial dynamics and a greatly increased fractional dependence on glycolysis rather than oxidative phosphorylation, compared to adult cardiomyocytes [3133]. To assess the usefulness of HL-1 as a model for cardioprotection by acidic reperfusion, we mimicked as closely as possible the protocol used in the Langendorff heart model while taking into account that compared to hearts exposed to no-flow ischemia, cultured HL-1 cardiomyocytes seem to require a substantially longer period of simulated ischemia to induce $\mathrm{I} / \mathrm{R}$ damage [e.g. 18], presumably because of their reduced dependence on oxidative phosphorylation [33]. The HL-1 cells were exposed to $5 \mathrm{~h}$ of simulated ischemia $\left(0.5 \% \mathrm{O}_{2}, 5 \% \mathrm{CO}_{2}\right.$, $\mathrm{HCO}_{3}{ }^{-}$buffering to $\mathrm{pH} 6.0$, increased $\mathrm{K}^{+}$, and no glucose), followed by $120 \mathrm{~min}$ reperfusion, of which the first 15 min was either at $\mathrm{pH} 7.4$ or $\mathrm{pH} 6.0$, and in the absence or presence of EIPA. HL-1 cells undergoing ischemia followed by 120 min neutral reperfusion exhibited a marked increase in both necrotic and apoptotic cell death compared to normoxic controls, consistent with previous reports by us and others [3, 18, 45]. However, in marked contrast to the findings in whole perfused hearts, neither apoptotic nor necrotic cell death of HL-1 cells under these conditions was attenuated by $15 \mathrm{~min}$ acidic reperfusion. This is in apparent contradiction to one earlier study in HL-1 cells, in which a brief acidic treatment was found to exert significant protection against I/R damage [45]. Notably, however, where we employed true hypoxia in combination with physiologically relevant $\mathrm{CO}_{2} / \mathrm{HCO}_{3}$ buffering, this study [45] employed a "simulated ischemia" protocol in which glucose- and mitochondrial metabolism is poisoned by cyanide and 2-deoxyglucose (2-DOG) to completely block both. Furthermore, $\mathrm{pH}$ was buffered artificially with $\mathrm{HEPES}$ rather than by $\mathrm{CO}_{2} / \mathrm{HCO}_{3}^{-}$, which means that all $\mathrm{HCO}_{3}^{-}$dependent $\mathrm{pH}$ regulation was prevented [45]. It may be noted that if we conduct our HL-1 cell experiments in the absence of $\mathrm{HCO}_{3}^{-}$, we also observe a protective effect of acidic $\mathrm{pH}$ against I/Rinduced chromatin condensation ( $\mathrm{n}=3$, data not shown). It thus seems likely that the difference stems from this marked difference in experimental conditions. The lack of protective effect of acidic $\mathrm{pH}$ in HL-1 cardiomyocytes in the present study - which with respect to buffering and hypoxia resemble more closely those of the native cardiomyocyte - may reflect that hypercontractureinduced damage does not contribute to death induced by $\mathrm{I} / \mathrm{R}$ in the non-contracting HL-1, or it can be due to differences in signaling via upstream effectors in the native heart and in the HL-1 cells. It has been reported that PostC attenuates cardiomyocyte apoptosis through inhibition of JNK and p38 MAPK [36]. In contrast, Liu and coworkers [38] demonstrated that p38 MAPK was activated as a response to hypoxic postconditioning in rat primary cardiomyocytes. Both JNK and p 38 MAPK have been shown to be strongly $\mathrm{pH}$ sensitive, being more active at alkaline than at acidic $\mathrm{pH}[28,46]$. Furthermore, Akt, another kinase implicated in PostC, is regulated by NHE1 [17]. In perfused rat hearts Akt activation was increased both after ischemia/reperfusion and, to a greater extent, after ischemic postconditioning [37]. We therefore tested the effects of brief acidic reperfusion on these kinases. I/R of HL-1 cardiomyocytes was, in line with earlier reports [37, 38], associated with a marked increase in the activity of JNK1/2 and Akt (but not of p38 MAPK), which were unaffected by post ischemic acidic or EIPA treatment. Thus, in HL-1 cardiomyocytes exposed to I/ $\mathrm{R}$, these kinases are not $\mathrm{pH}$ sensitive in the range tested.

Considered the marked protective effect of acidic reperfusion/ischemic postconditioning in intact hearts and

Andersen/Bentzen/Salling/Klingberg/Kanneworff/Grunnet/Pedersen 
the lack of such effects in HL-1 cardiomyocytes, caution must clearly be exerted in using HL-1 cells for studies of simulated PostC, at least in the form of acidic reperfusion. Although other factors, such as the role of reduced hypercontracture in PostC protection in the intact heart [8] are likely to contribute, we speculate that the major reason for this discrepancy is the markedly different metabolism and mitochondrial function between HL-1 cells and adult cardiomyocytes [31-33]. Also a $15 \mathrm{~min}$ treatment with EIPA failed to protect the HL-1 cells from reperfusion damage. This is, to our knowledge, the first study of brief, post-ischemic NHE1 inhibition. The lack of protection by NHE1 inhibition is in good agreement with recent studies by us and others pointing to a modest protective, rather than a detrimental role of NHE1 after cardiac ischemia $[18,19]$. Addressing this question in the intact heart will necessitate tight spatial and temporal control of cardiac $\mathrm{pH}_{\mathrm{i}}$ and $\mathrm{pH}_{\mathrm{o}}$, a methodologically challenging feat - but should be carried out in future studies.

In conclusion, a 15 min acidic treatment at the onset of reperfusion is at least as protective as PostC against
$\mathrm{I} / \mathrm{R}$ damage in intact rat hearts, whereas inhibition of NHE1 is detrimental. In contrast, in HL-1 cardiomyocytes, necrotic and apoptotic death induced by $\mathrm{I} / \mathrm{R}$ in the presence of $\mathrm{HCO}_{3}{ }^{-}$are not attenuated by a $15 \mathrm{~min}$ acidic exposure at the onset of reperfusion, arguing against the use of this model for PostC studies. Finally, I/R in HL-1 cardiomyocytes is associated with a $\mathrm{pH}-$ and NHE1independent increase in the activity of JNK $1 / 2$ and Akt, but not of p38 MAPK.

\section{Acknowledgements}

This work was supported by the Danish National Research Council (SFP, MG), the Gangsted foundation (SFP), The Danish National Research Foundation Centre for Cardiac Arrhythmia (BHB), The Novo Nordisk Foundation, The Aase and Ejnar Danielsen Foundation (MG) and the Danish Heart Association (ADA). We are grateful to Vibe Nylander, Andrius Gorbatenko and Søren Lek Johansen for expert technical assistance.

\section{References}

Ferdinandy P, Schulz R, Baxter GF: In- 6 teraction of cardiovascular risk factors with myocardial ischemia/reperfusion injury, preconditioning, and postconditioning. Pharmacol Rev 2007;59:418-458.

2 Hausenloy DJ, Yellon DM: Time to take myocardial reperfusion injury seriously. N Engl J Med 2008;359:518-520.

-3 Vinten-Johansen J, Granfeldt A, Mykytenko J, Undyala VV, Dong Y, Przyklenk K: The Multi-dimensional Physiological Responses to Postconditioning. Antioxid Redox Signal 2011;14:791-810.

-4 Penna C, Mancardi D, Raimondo S, Geuna S, Pagliaro P: The paradigm of postconditioning to protect the heart. J Cell Mol Med 2008;12:435-458.

\$ Zhao ZQ, Corvera JS, Halkos ME, 9 Kerendi F, Wang NP, Guyton RA, VintenJohansen J: Inhibition of myocardial injury by ischemic postconditioning during reperfusion: comparison with ischemic preconditioning. Am J Physiol Heart Circ Physiol 2003;285:H579H588.
Hausenloy DJ, Lecour S, Yellon DM: Reperfusion Injury Salvage Kinase and Survivor Activating Factor Enhancement Prosurvival Signaling Pathways in Ischemic Postconditioning: Two Sides of the Same Coin. Antioxid Redox Signal 2011;14:893-907.

Pedersen SF, O'Donnell ME, Anderson SE, Cala PM: Physiology and pathophysiology of $\mathrm{Na}^{+} / \mathrm{H}^{+}$exchange and $\mathrm{Na}^{+}$$\mathrm{K}^{+}-2 \mathrm{Cl}^{-}$cotransport in the heart, brain, and blood. Am J Physiol Regul Integr Comp Physiol 2006;291:R1-25. Inserte J, Ruiz-Meana M, RodriguezSinovas A, Barba I, Garcia-Dorado D: Contribution of delayed intracellular $\mathrm{pH}$ recovery to ischemic postconditioning protection. Antioxid Redox Signal 2011;14:923-939.

Murphy E, Steenbergen C: Mechanisms underlying acute protection from cardiac ischemia-reperfusion injury. Physiol Rev 2008;88:581-609.

Cohen MV, Yang XM, Downey JM: The $\mathrm{pH}$ hypothesis of postconditioning: staccato reperfusion reintroduces oxygen and perpetuates myocardial acidosis. Circulation 2007;115:1895-1903.
Inserte J, Barba I, Hernando V, Abellan A, Ruiz-Meana M, Rodriguez-Sinovas A, Garcia-Dorado D: Effect of acidic reperfusion on prolongation of intracellular acidosis and myocardial salvage. Cardiovasc Res 2008;77:782-790.

-12 Inserte J, Barba I, Poncelas-Nozal M, Hernando V, Agullo L, Ruiz-Meana M, Garcia-Dorado D: cGMP/PKG pathway mediates myocardial postconditioning protection in rat hearts by delaying normalization of intracellular acidosis during reperfusion. J Mol Cell Cardiol 2011;50:903-909

13 Hori M, Kitakaze M, Sato H, Takashima S, Iwakura K, Inoue M, Kitabatake A, Kamada T: Staged reperfusion attenuates myocardial stunning in dogs. Role of transient acidosis during early reperfusion. Circulation 1991;84:2135-2145.

14 Inserte J, Barba I, Hernando V, GarciaDorado D: Delayed recovery of intracellular acidosis during reperfusion prevents calpain activation and determines protection in postconditioned myocardium. Cardiovasc Res 2009;81:116-122.

Vaughan-Jones RD, Spitzer KW, Swietach $\mathrm{P}$ : Intracellular $\mathrm{pH}$ regulation in heart. J Mol Cell Cardiol 2009;46:318-331. 
16 Pedersen SF, Lauritzen G, Andersen AD: The $\mathrm{Na}^{+} / \mathrm{H}^{+}$exchanger NHE1: diverse roles in regulation of cellular signaling pathways controlling proliferation, motility, and survival. Research Signpost 2011; in press.

17 Schelling JR, Abu Jawdeh BG: Regulation of Cell Survival by $\mathrm{Na}^{+} / \mathrm{H}^{+}$Exchanger- 1 (NHE1). Am J Physiol Renal Physiol 2008;295:F625-632.

18 Andersen AD, Poulsen KA, Lambert IH, Pedersen SF: HL-1 mouse cardiomyocyte injury and death after simulated ischemia and reperfusion: roles of $\mathrm{pH}, \mathrm{Ca}^{2+}$-independent phospholipase A2, and $\mathrm{Na}^{+} / \mathrm{H}^{+}$ exchange. Am J Physiol Cell Physiol 2009;296:C1227-C1242.

19 Karki P, Fliegel L: Overexpression of the NHE1 isoform of the $\mathrm{Na}^{+} / \mathrm{H}^{+}$exchanger causes elevated apoptosis in isolated cardiomyocytes after hypoxia/reoxyge nation challenge. Mol Cell Biochem 2010;338:47-57.

20 Mentzer RM, Bartels C, Bolli R, Boyce S, Buckberg GD, Chaitman B, Haverich A, Knight J, Menasche P, Myers ML, Nicolau J, Simoons M, Thulin L, Weisel RD: Sodium-hydrogen exchange inhibition by cariporide to reduce the risk of ischemic cardiac events in patients undergoing coronary artery bypass grafting: results of the EXPEDITION study. Ann Thorac Surg 2008;85:1261-1270. Zeymer U, Suryapranata H, Monassier JP, Opolski G, Davies J, Rasmanis G, Linssen G, Tebbe U, Schroder R, Tiemann R, Machnig T, Neuhaus KL: The $\mathrm{Na}^{+} / \mathrm{H}^{+}$ exchange inhibitor eniporide as an adjunct to early reperfusion therapy for acute myocardial infarction. Results of the evaluation of the safety and cardioprotective effects of eniporide in acute myocardial infarction (ESCAMI) trial. J Am Coll Cardiol 2001;38:1644-1650.

-22 Ovize M, Baxter GF, Di LF, Ferdinandy P, Garcia-Dorado D, Hausenloy DJ, Heusch G, Vinten-Johansen J, Yellon DM, Schulz R: Postconditioning and protection from reperfusion injury: where do we stand? Position paper from the Working Group of Cellular Biology of the Heart of the European Society of Cardiology. Cardiovasc Res 2010;87:406-423.

23 Baines CP: The cardiac mitochondrion nexus of stress. Annu Rev Physiol 2010;72:61-80

24 Hausenloy DJ: Signalling pathways in ischaemic postconditioning. Thromb $>35$ Haemost 2009;101:626-634.

25 Hausenloy DJ, Yellon DM: Survival kinases in ischemic preconditioning and postconditioning. Cardiovasc Res 2006; 70:240-253.

26 Darmellah A, Rucker-Martin C, Feuvray D: ERM proteins mediate the effects of $\mathrm{Na}^{+} / \mathrm{H}^{+}$exchanger (NHE1) activation in cardiac myocytes. Cardiovasc Res 2009;81:294-300.
27 Haworth RS, McCann C, Snabaitis AK, Roberts NA, Avkiran M: Stimulation of the plasma membrane $\mathrm{Na}^{+} / \mathrm{H}^{+}$exchanger NHE1 by sustained intracellular acidosis. Evidence for a novel mechanism mediated by the ERK pathway. J Biol Chem 2003;278:31676-31684.

Pedersen SF, Darborg BV, Rasmussen M, Nylandsted J, Hoffmann EK: The $\mathrm{Na}^{+}$/ $\mathrm{H}^{+}$exchanger, NHE1, differentially regulates mitogen-activated protein kinase subfamilies after osmotic shrinkage in Ehrlich Lettre Ascites cells. Cell Physiol Biochem 2007;20:735-750.

-29 Pedersen SF, Darborg BV, Rentsch ML, Rasmussen M: Regulation of mitogenactivated protein kinase pathways by the plasma membrane $\mathrm{Na}^{+} / \mathrm{H}^{+}$exchanger, NHE1. Arch Biochem Biophys 2007;462:195-201

$\checkmark 30$ Claycomb WC, Lanson NA, Stallworth BS, Egeland DB, Delcarpio JB, Bahinski A, Izzo NJ: HL-1 cells: a cardiac muscle cell line that contracts and retains phenotypic characteristics of the adult cardiomyocyte. Proc Natl Acad Sci USA 1998;95:2979-2984.

Eimre M, Paju K, Pelloux S, Beraud N, Roosimaa M, Kadaja L, Gruno M, Peet N, Orlova E, Remmelkoor R, Piirsoo A, Saks V, Seppet E: Distinct organization of energy metabolism in HL-1 cardiac cell line and cardiomyocytes. Biochim Biophys Acta 2008;1777:514-524.

\$2 Beraud N, Pelloux S, Usson Y, Kuznetsov AV, Ronot X, Tourneur Y, Saks V: Mitochondrial dynamics in heart cells: very low amplitude high frequency fluctuations in adult cardiomyocytes and flow motion in non beating $\mathrm{Hl}-1$ cells. Bioenerg Biomembr 2009;41:195-214. Monge C, Beraud N, Tepp K, Pelloux S, Chahboun S, Kaambre T, Kadaja L, Roosimaa M, Piirsoo A, Tourneur Y, Kuznetsov AV, Saks V, Seppet E: Comparative analysis of the bioenergetics of adult cardiomyocytes and nonbeating HL1 cells: respiratory chain activities, glycolytic enzyme profiles, and metabolic fluxes. Can J Physiol Pharmacol 2009;87:318-326

34 Bentzen BH, Osadchii O, Jespersen T, Hansen RS, Olesen SP, Grunnet M: Activation of big conductance $\mathrm{Ca}^{2+}$-activated $\mathrm{K}^{+}$channels (BK) protects the heart against ischemia-reperfusion injury. Pflugers Arch 2009;457:979-988.

Fishbein MC, Meerbaum S, Rit J, Lando U, Kanmatsuse K, Mercier JC, Corday E, Ganz W: Early phase acute myocardial infarct size quantification: validation of the triphenyl tetrazolium chloride tissue enzyme staining technique. Am Heart J 1981;101:593-600.

36 Sun HY, Wang NP, Halkos M, Kerendi F, Kin H, Guyton RA, Vinten-Johansen J, Zhao ZQ: Postconditioning attenuates cardiomyocyte apoptosis via inhibition of JNK and p38 mitogen-activated protein kinase signaling pathways. Apoptosis 2006;11:1583-1593.

-37 Tsang A, Hausenloy DJ, Mocanu MM, Yellon DM: Postconditioning: a form of "modified reperfusion" protects the myocardium by activating the phosphatidylinositol 3-kinase-Akt pathway. Circ Res 2004;95:230-232.

$\checkmark 38$ Liu XH, Zhang ZY, Sun S, Wu XD: Ischemic postconditioning protects myocardium from ischemia/reperfusion injury through attenuating endoplasmic reticulum stress. Shock 2008;30:422427.

Fujita M, Asanuma H, Hirata A, Wakeno M, Takahama H, Sasaki H, Kim J, Takashima S, Tsukamoto O, Minamino T, Shinozaki Y, Tomoike H, Hori M, Kitakaze M: Prolonged transient acidosis during early reperfusion contributes to the cardioprotective effects of postconditioning. Am J Physiol Heart Circ Physiol 2007;292:H2004-H2008. Xiao XH, Allen DG: Role of $\mathrm{Na}^{+} / \mathrm{H}^{+}$exchanger during ischemia and preconditioning in the isolated rat heart. Circ Res 1999;85:723-730.

Liu H, Cala PM, Anderson SE: Na/H exchange inhibition protects newborn heart from ischemia/reperfusion injury by limiting $\mathrm{Na}^{+}$-dependent $\mathrm{Ca}^{2+}$ overload. J Cardiovasc Pharmacol 2010;55:227-233. ten Hove M, van Emous JG, van Echteld $\mathrm{CJ}$ : $\mathrm{Na}^{+}$overload during ischemia and reperfusion in rat hearts: comparison of the $\mathrm{Na}^{+} / \mathrm{H}^{+}$exchange blockers EIPA, cariporide and eniporide. Mol Cell Biochem 2003;250:47-54.

Garciarena CD, Caldiz CI, Correa MV, Schinella GR, Mosca SM, Chiappe de Cingolani GE, Cingolani HE, Ennis IL: $\mathrm{Na}^{+} / \mathrm{H}^{+}$exchanger-1 inhibitors decrease myocardial superoxide production via direct mitochondrial action. J Appl Physiol 2008;105:1706-1713

Miura T, Liu Y, Goto M, Tsuchida A, Miki T, Nakano A, Nishino Y, Ohnuma Y, Shimamoto K: Mitochondrial ATPsensitive $\mathrm{K}^{+}$channels play a role in cardioprotection by $\mathrm{Na}^{+} / \mathrm{H}^{+}$exchange inhibition against ischemia/reperfusion injury. J Am Coll Cardiol 2001;37:957-963. Ruiz-Meana M, Pina P, Garcia-Dorado D, Rodriguez-Sinovas A, Barba I, MiroCasas E, Mirabet M, Soler-Soler J: Glycine protects cardiomyocytes against lethal reoxygenation injury by inhibiting mitochondrial permeability transition. J Physiol 2004;558:873-882.

Rentsch ML, Ossum CG, Hoffmann EK, Pedersen SF: Roles of $\mathrm{Na}^{+} / \mathrm{H}^{+}$exchange in regulation of p38 mitogen-activated protein kinase activity and cell death after chemical anoxia in NIH3T3 fibroblasts. Pflugers Arch 2007;454:649662 . 